\title{
Influence of Root Morphology on Ecological Slope Protection
}

\author{
JI Xiaolei ${ }^{1}$, XULanlan $^{1}$, YANG Guoping ${ }^{2}$ \\ ${ }^{1}$ College of Construction Engineering, Jiangsu Open University, Nanjing, Jiangsu 210019, China ${ }^{2}$ Nanjing city vocational college, \\ Nanjing, Jiangsu 211200, China
}

\begin{abstract}
Ecological slope protection is of great importance for preventing the water and soil loss on bare slopes, improving the ecological environment, and realizing the sustainable ecosystem development. The root-soil composite slope consisting of homogenous soil mass and oleander root system was taken as the study object. Based on the mechanics principle of soil reinforcement by roots in ecological slope protection, the influences of the lateral root quantity of plants and included angle between main root and lateral root on the slope protection were investigated via the finite element (FE) software ABAQUS. The simulation results show that the larger the quantity of lateral roots, the more obvious the displacement reduction of the soil mass on the slope surface will be. The slope protection effect varies with the root morphology, the included angle between main root and lateral root is an important factor influencing the slope protection effect of plants, and the slope protection effect at included angle of $30^{\circ}$ is apparently superior to that at $90^{\circ}$. The research results can provide a theoretical support for the plant selection in the ecological slope protection.

Classification No.: S284

Literature Code: A

Article No.:
\end{abstract}

\section{Introduction}

In recent years, all kinds of engineering construction activities have been booming, such as expressway and railway engineering, port engineering, energy development and utilization engineering, mineral resource mining, etc., These engineering construction activities will unavoidably form many bare rocky slopes, which not only destruct the vegetations and soil, damage the ecological landscapes but also easily give rise to water and soil loss, and induce geological disasters like collapse, landslide and debris flow [1] [2].

With the continuously deepening researches on slope engineering, various slope protection methods have been proposed, such as slope-cutting unloading, slope foot pressing, slope surface protection, slide-resistant piles, anchor bolt (cable), hole reinforcement, water drainage, barricade, comprehensive reinforcement method, etc. [3]. Among the commonly used slope reinforcement methods, large-scale construction machineries and artificial materials are required, which will unavoidably impose environmental harms and consume a large amount of resources. Therefore, it is essential to put forward an environmentally friendly slope treatment method. Cao Z $\mathrm{H}$ found that recovering the degraded vegetation system was significant for preventing the water and soil loss, improving the ecological environment, and realizing the sustainable ecosystem development [4]. Meanwhile, the topography and vegetation recovery could exert a great synergistic effect on the species diversity [5]. Studies show that rainfall is the primary factor triggering slope instability and causing accidents like collapse and landslide, and the plant root system also has a remarkable bearing on the anti-scouring performance of slopes[6] [7].

The slope protection by plant roots has aroused extensive attention by virtue of simple construction, environmentally friendly characteristic and excellent reinforcing effect on shallow slope [8] [9]. At present, slope reinforcement has been realized through vegetation recovery in some countries and regions [10], and meanwhile, numerous scholars have conducted a lot of research work according to the reinforcement mechanism of plant roots. Akhil Gary [11] established the correlations of slope stability safety coefficient with root percentage and root depth in soil mass on the slope through a numerical simulation. Du G Q [12] studied the slope protection mechanism of plants, and the results showed that the plant roots could effectively strengthen the soil stability on the slope. Wang G Y [13] conducted a numerical analysis of a vegetation-covered slope by 
combining the cloud simulation technology with 3D surveying and mapping technology, and this research method was more adaptable to the practical slope protection engineering application. J.R. Greenwood[14] and Ferraiolo[15] summarized the stabilizing effect of vegetations on the slope, including hydraulic mechanism and mechanical mechanism of machinery. Jianye, M. A. et al. [16] studied the rainfall reallocation process under different modes of vegetation recovery and the influence on the stability of soil layers. Kim, J. H. et al. [17] studied the influence of plant growth time on the slope stability in different areas, and analyzed the influence of vegetation (or no vegetation) on the slope stability in tropical, subtropical and temperate areas susceptible to landslide and earthquake through actual measurement and numerical simulation. Wu et al. [18] put forward the cementing relation between root and soil, conducted shear test of roots and tensile test of soil, and thus the research on the mechanical mechanism of soil reinforcement by roots jumped to a new height.

As aforementioned, many scholars have probed into the reinforcement mechanism of plants in slope protection, and its influence on slope stability. However, there are few 3D modeling researches based on vegetation root morphology. Given this, oleander was used as the slope protection plant in this research, and then the influences of the lateral root quantity and included angle between main root and lateral root on the ecological slope protection were investigated via the $3 \mathrm{D}$ numerical analysis software ABAQUS, expecting to explore the ecological slope protection mechanism and establish the theory regarding the application of plant slope protection technology.

\section{Finite Element Modeling}

The root-soil composite model was regarded as a $3 \mathrm{D}$ separating-type model via the ABAQUS software, the soil material was regarded as an ideal elastic-plastic constitutive model following the Mohr-Coulomb failure criterion, the slope was simulated using C3D8 cells and root was simulated using T3D2 cells, and the embedded root-slope contact was employed. It was assumed that when connected together, the root and soil could automatically realize compatibility of displacement, the root-soil movement on the contact surface was neglected, and the material characteristics of the root and soil themselves were adopted. According to the theory of soil reinforcement by plant roots, the root was simulated into a reinforcing material with a certain strength and embedded into the soil mass on the slope, and then a reinforced soil layer with a certain thickness was formed on the slope surface.

\subsection{Root simplification}

A total of 40 standard oleander roots were collected from Nanjing-Changzhou Expressway for a parametric analysis. From Figure 1 and Figure 2, the oleander roots belonged to taproots, the diameter difference value between main root and lateral root was not large, the average burial depth and average diameter were $58 \mathrm{~cm}$ and $9 \mathrm{~mm}$, respectively, with strong resistance to tension, and the average tensile strength was $16.23 \mathrm{MPa}$. The roots were of complex morphologies, and they formed a net-shaped structure on the soil mass to exert the effect of protecting the soil mass. The natural root morphology was relatively complicated, the root model could not be simulated strictly according to the root growth morphology, so the natural roots were simplified according to their morphological characteristics, where the main root and lateral root shared the same cross section with diameter of $10 \mathrm{~mm}$, the main root was $600 \mathrm{~mm}$ in length and the lateral root was 200 $\mathrm{mm}$ in length, and the number lateral roots was divided into three circumstances - 4,8 and 12 , specifically as shown in Figure 3. The included angle between main root and lateral root was set as $30^{\circ}$ and $90^{\circ}$ (Figure 4).

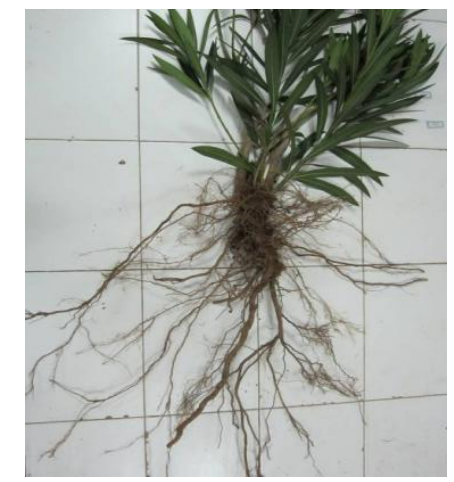

Figure 1 Oleander Root

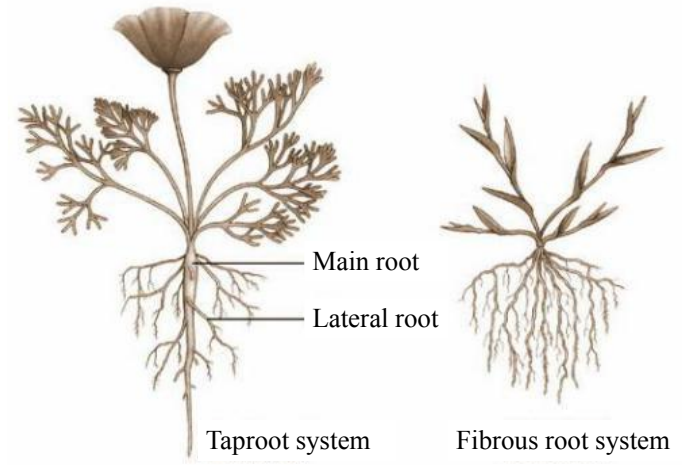

Figure 2 Comparison Chart of Root Systems
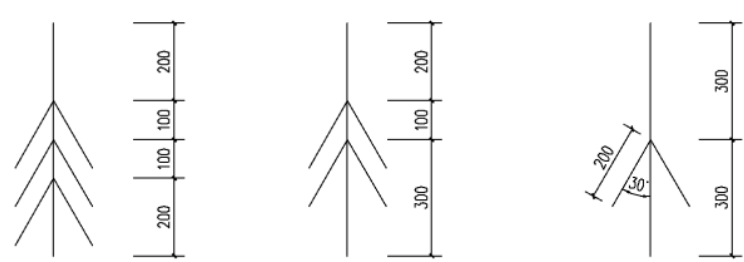

Figure 3 Schematic Diagram of Root Simplification(unit: $\mathrm{mm})$ 


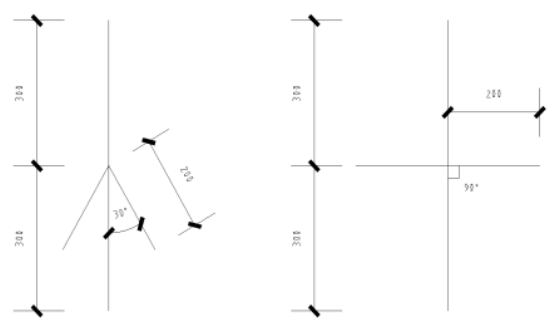

Figure 4 Schematic Diagram of Included Angle between Main Root and Lateral Root (unit: $\mathrm{mm}$ )

\subsection{Slope section for calculation}

As the slope protection by plants was only applicable to slopes with small slope gradients, in the numerical calculation, the slope gradient was set as $30^{\circ}$, slope length as $2 \mathrm{~m}$ and plant spacing as 2 roots/m as shown in Figure 5. The numerical calculation model in this paper was a 3D model. The 3D strain model analysis was carried out to solve the 3D strain problem, the model boundary was free boundary, the Z-directional constraint was used in the left and right directions of the model, XYZ three-directional constraints were used for the bottom surface, and in order to realize coordinated deformation of the root and soil mass, each node of the root in the model was coupled with the node on the soil mass nearest to it, the model grid chart was divided according to the grid size of $0.25 \mathrm{~m}$, and there were totally 27.040 grid cells in the soil model.

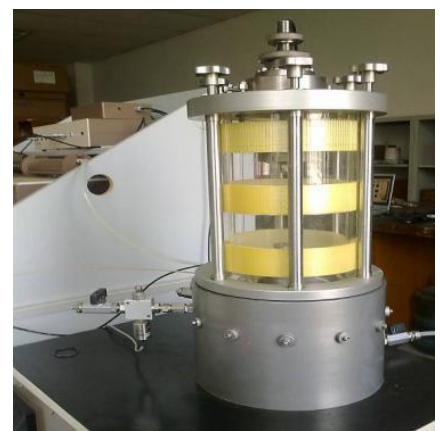

Figure 7 GDS Triaxial Testing Machine

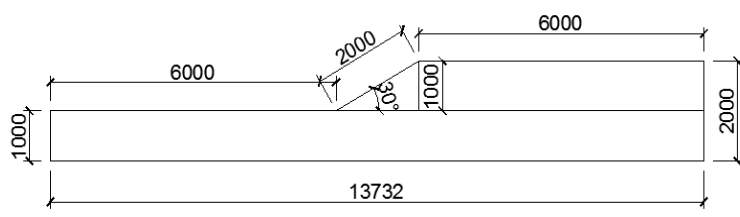

Figure 5 Schematic Diagram of Slope Simplification (unit: $\mathrm{mm}$ )

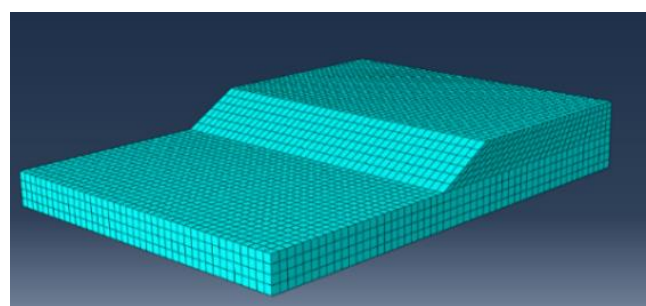

Figure 6 Grid Chart of Slope Numerical Calculation Model

\subsection{Parameters in finite element numerical calculation}

The soil mass required in the test was disturbed soil, both oleander root and soil mass came from Liyang segment of Nanjing-Changzhou Expressway, the physical parameters of the soil sample were acquired through the GDS triaxial test, and the test instrument was shown in Figure 7. The basic parameters of the roots were measured by a TGH2B microcomputer controlled universal testing machine (Figure 8). The test data were listed in Table 1 and Table 2.

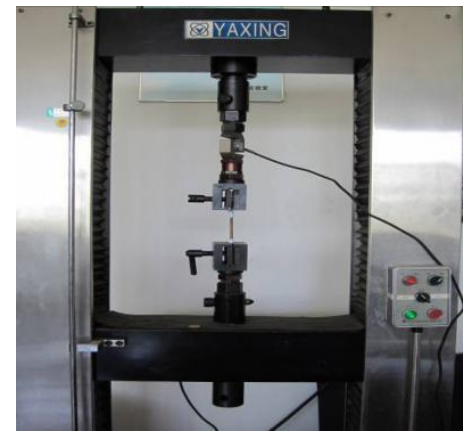

Figure 8 Universal Testing Machine

Table 1 Material Parameters of Soil Mass

\begin{tabular}{ccccccc}
\hline Material & $\begin{array}{c}\text { Elasticity } \\
\text { modulus } \\
(\mathrm{MPa})\end{array}$ & Poisson's ratio & $\begin{array}{c}\text { Cohesion C } \\
(\mathrm{Kpa})\end{array}$ & $\begin{array}{c}\text { Internal } \\
\text { friction angle } \\
\left({ }^{\circ}\right)\end{array}$ & $\begin{array}{c}\text { Unit weight } \\
(\mathrm{KN} \cdot \mathrm{m}-3)\end{array}$ & $\begin{array}{c}\text { Moisture } \\
\text { content }(\%)\end{array}$ \\
\hline Soil mass & 10 & 0.3 & 8.3 & 16 & 18 & 26.6 \\
\hline
\end{tabular}

Table 2 Material Parameters of Oleander Root

\begin{tabular}{ccccc}
\hline Material & $\begin{array}{c}\text { Elasticity } \\
\text { modulus } \\
(\mathrm{MPa})\end{array}$ & $\begin{array}{c}\text { Poisson's } \\
\text { ratio }\end{array}$ & $\begin{array}{c}\text { Diameter } \\
(\mathrm{mm})\end{array}$ & $\begin{array}{c}\text { Length } \\
(\mathrm{mm})\end{array}$ \\
\hline Root & 10 & 0.3 & 10 & 60 \\
\hline
\end{tabular}




\section{Numerical Calculation Results and Analysis}

In order to explore the influence of the oleander roots on the slope protection, a finite element numerical simulation was carried out for the plant-free slope and plant-covered slope, and the influences of the roots with different morphologies on the soil displacement field on the slope surface were studied. The nephogram of finite element displacement field calculation of the slope is shown in Figure 9.

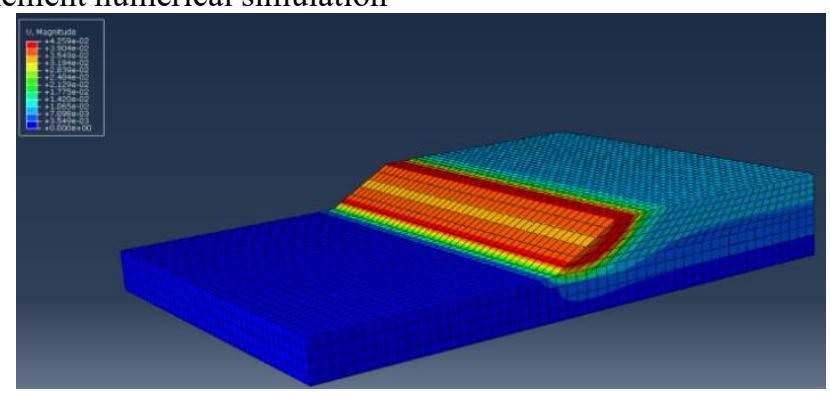

Figure 9 Nephograph of Finite Element Displacement Field Calculation of the Slope

Based on an analysis of the calculation results obtained through the finite element software, the maximum horizontal displacement, vertical displacement and total displacement of the slope surface without plant roots were $4.058 \mathrm{~mm}, 3.452 \mathrm{~mm}$ and $4.259 \mathrm{~mm}$, respectively. The calculation results showed that the soil displacement field on the slope experienced obvious changes after the plant roots with different lateral root quantities and different included angles between main root and lateral root were arranged on the slope. The concrete data are displayed in Table 3.

The influence curve chart of the roots with different included angle between main root and lateral root on the soil displacement field on the slope surface was drawn (Figure 10) according to the data in the table.

Table 3 Soil Displacement on Slope Surface

\begin{tabular}{ccccc}
\hline \multirow{2}{*}{$\begin{array}{c}\text { Included } \\
\text { angle } \\
\text { root } \\
\text { quantity }\end{array}$} & $\begin{array}{c}\text { Horizontal } \\
\text { main root } \\
\text { and lateral } \\
\text { root }\left(^{\circ}\right)\end{array}$ & $\begin{array}{c}\text { Vertical } \\
\text { displacement } \\
(\mathrm{mm})\end{array}$ & $\begin{array}{c}\text { Total } \\
\text { displacement } \\
(\mathrm{mm})\end{array}$ & $\begin{array}{c}\text { displacement } \\
(\mathrm{mm})\end{array}$ \\
\hline \multirow{2}{*}{4} & 30 & 3.563 & 3.113 & 3.791 \\
& 90 & 3.935 & 3.370 & 4.145 \\
\multirow{2}{*}{12} & 30 & 3.311 & 2.937 & 3.547 \\
& 90 & 3.933 & 3.369 & 4.144 \\
& 30 & 3.119 & 2.806 & 3.369 \\
& 90 & 3.801 & 3.279 & 4.022 \\
\hline
\end{tabular}

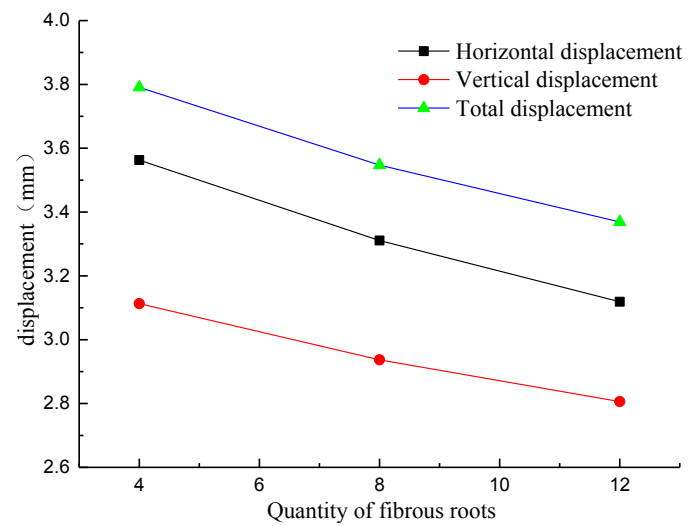

(a) Root with Included Angle between Main Root and Lateral Root of $30^{\circ}$ 


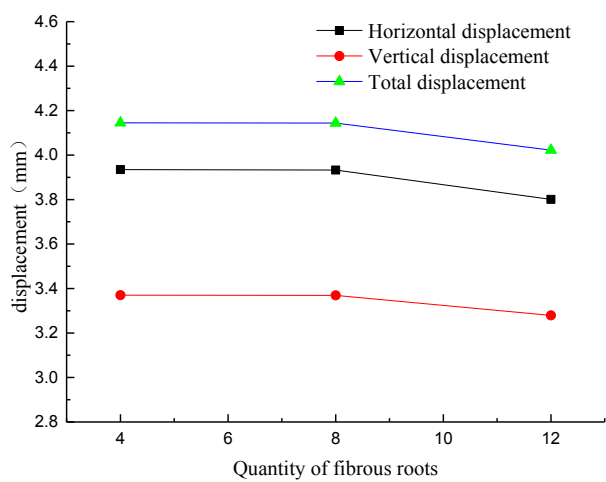

(b) Root with Included Angle between Main Root and Lateral Root of $90^{\circ}$

Figure 10 Influence Curve Chart of Lateral Root Quantity on Soil Displacement on Slope Surface

It could be known through the above figure that when planted into the slope, the roots could effectively reduce the soil displacement on the slope surface, and the larger the lateral root quantity, the greater the displacement reduction would be. Different included angles between main root and lateral root could exert different influences on the displacement on the slope surface. By comparing Figure 10 (a) and (b), the roots with included angle of $30^{\circ}$ reduced the soil displacement on the slope more considerably, with more effective slope protection effect, which was identical with the indoor GDS triaxial compression test result of the root-soil composite slope. The root with included angle of $30^{\circ}$ had more complicated contact with the soil mass than the root with included angle of $90^{\circ}$. When the soil mass was under an external load, the root was more firmly cohered to the soil mass, which could effectively increase the force facilitating the friction between root and soil mass, and as a result, the root could not be easily pulled out of the soil, thus effectively exerting the strong resistance of root to tension.

The relationships between lateral root quantity of oleander roots at different included angles between main root and lateral root, and the soil displacements on the slope can be expressed by the following formula:

Fitting formula under included angle of $30^{\circ}$ :

Horizontal displacement:

$$
y=-0.0555 x+3.775, \mathrm{R}^{2}=0.9879
$$

Vertical displacement:

$$
y=-0.03837 x+3.259, \mathrm{R}^{2}=0.9858
$$

Total displacement:

$$
y=-0.05275 x+3.991, \mathrm{R}^{2}=0.98382
$$

Fitting formula under included angle of $30^{\circ}$ :

Horizontal displacement:

$$
y=-0.01675 x+4.02367, \mathrm{R}^{2}=0.5538
$$

Vertical displacement:

$$
y=-0.01137 x+3.43033, \mathrm{R}^{2}=0.51648
$$

Total displacement:

$$
y=-0.01537 x+4.22667, \mathrm{R}^{2}=0.51219
$$

From the above fitting formulas, the influence of the root with included angle of $30^{\circ}$ on the slope displacement presented a high linear correlation with the lateral root quantity, while the influence of the root with included angle of $90^{\circ}$ on the slope displacement presented a weak linear correlation with the lateral root quantity, indicating that the root with included angle of $30^{\circ}$ exerted more regular effect on the slope displacement when the lateral root quantity increased.

\subsection{Influence of included angle between main root and lateral root on horizontal displacement of soil mass on slope}

The comparative histogram regarding the influences of the root with included angle of $30^{\circ}$ and that with included angle of $90^{\circ}$ on the horizontal displacement of the soil mass on the slope was drawn according to the calculated data as shown in Figure 11.

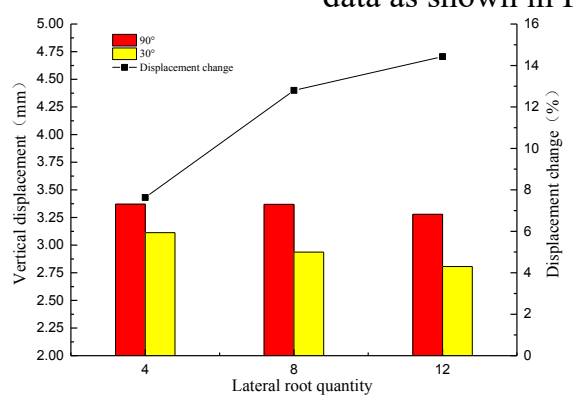

Figure 11 Histogram of Horizontal Displacement on Slope Surface with the Change of Lateral Root Quantity

From the figure, the horizontal displacement of the slope planted with the roots under included angle of $30^{\circ}$ was evidently smaller than that of the slope planted with the roots under included angle of $90^{\circ}$. The influences of the slope protective plants with included angles of $30^{\circ}$ and $90^{\circ}$ on the horizontal displacement of the slope were compared, the horizontal displacement was reduced by $9.45 \%$ through the 4-lateral-root system, by $15.8 \%$ 
through the 8-lateral-root system, and by $17.9 \%$ through the 12-lateral-root system. With the increase of the lateral root quantity, the included angle between main root and lateral root exerted a more and more obvious effect on the horizontal displacement.

\subsection{Influence of included angle between main root and lateral root in plant root system on vertical displacement of soil mass on slope}

The comparative histogram regarding the influences of the root with included angle of $30^{\circ}$ and that with included angle of $90^{\circ}$ on the vertical displacement of the soil mass on the slope was drawn according to the calculated data as shown in Figure 12.

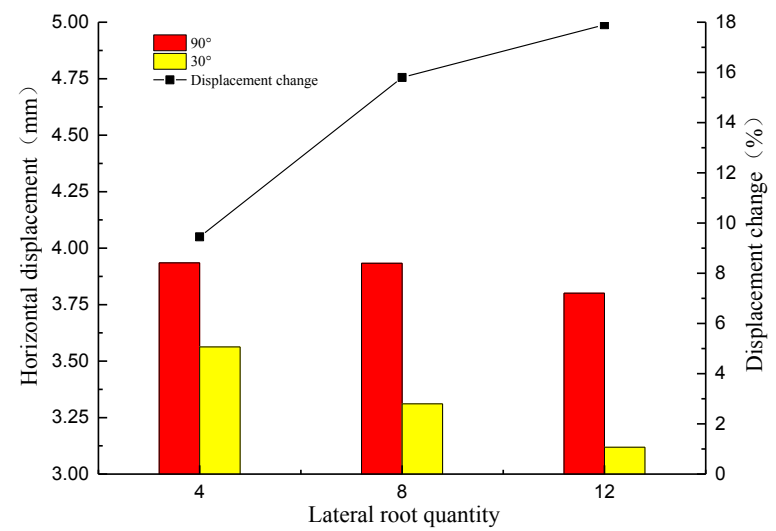

Figure 12 Histogram of Vertical Displacement on Slope Surface with the Change of Lateral Root Quantity

It could be known from the figure that the vertical displacement of the slope planted with the roots under included angle of $30^{\circ}$ was evidently smaller than that of the slope planted with the roots under included angle of $90^{\circ}$. The influences of the slope protective plants with included angles of $30^{\circ}$ and $90^{\circ}$ on the vertical displacement of the slope were compared, the vertical displacement was reduced by $7.63 \%$ through the 4 -lateralroot system, by $12.8 \%$ through the 8 -lateral-root system, and by $14.43 \%$ through the 12-lateral-root system. Just like the change of horizontal displacement of the soil mass on the slope, the included angle between main root and lateral root exerted a greater and greater effect on the vertical displacement of the slope with the increase of the lateral root quantity. In comparison with the horizontal displacement, the reduction amplitude of vertical displacement was smaller, so the influence of the plant roots on the soil mass on the slope was more obviously manifested by the inhibition of slippage of soil mass towards the slope surface, and prevention of water and soil loss on the slope.

\subsection{Influence of included angle between main root and lateral root in plant root system on total displacement of soil mass on slope}

The comparative histogram regarding the influences of the root with included angle of $30^{\circ}$ and that with included angle of $90^{\circ}$ on the total displacement of the soil mass on the slope was drawn according to the calculated data as shown in Figure 13.

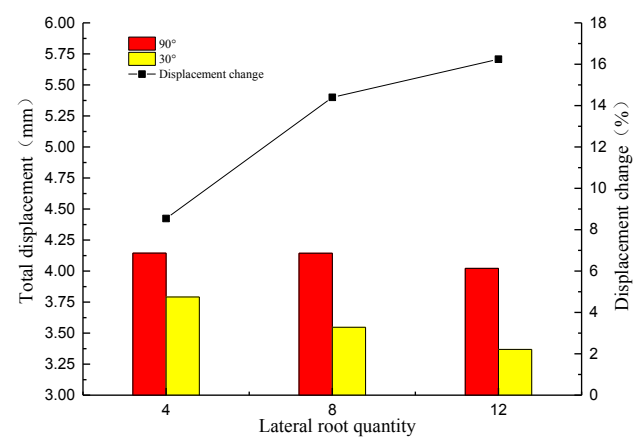

Figure 13 Histogram of Total Displacement on Slope Surface with the Change of Lateral Root Quantity

As shown in the above figure, the total displacement of the slope planted with the roots under included angle of $30^{\circ}$ was evidently smaller than that of the slope planted with the roots under included angle of $90^{\circ}$. The influences of the slope protective plants with included angles of $30^{\circ}$ and $90^{\circ}$ on the total displacement of the slope were compared, the total displacement was reduced by $8.54 \%$ through the 4-lateral-root system, by $14.4 \%$ through the 8 - lateral-root system, and by $16.24 \%$ through the 12 -lateralroot system. As the lateral root quantity increased, the reduction amplitude of total displacement of the soil mass on the slope surface became larger and larger thanks to the roots with included angle of $30^{\circ}$. 


\section{Conclusions}

(1) The slope protection effect varies with the root morphology, where the slope protection effect of the roots with included angle between main root and lateral root of $30^{\circ}$ is apparent better than that of the roots with included angle of $90^{\circ}$, and the included angle is an important factor influencing the slope protection effect of the plants. The root with included angle of $30^{\circ}$ forms a larger scope of contact with the soil layer on the slope than the root with included angle of $90^{\circ}$, the scope of the formed net-shaped structure is also broader, so it can more effectively reduce the soil displacement on the slope surface, and improve the slope resistance to water and soil loss.

(2) In the numerical calculation, the main root and lateral root in the oleander root system are processed on the same section without consideration of the anchoring effect of main root, and the main root and lateral root jointly act upon the soil mass to form a net-shaped structure with large stiffness. Under the action of external load, this structure can effectively transfer the external force to the surrounding soil masses through the stress dispersion effect, and form a root-soil composite slope to jointly resist against the external load, thus strengthening the resistance of soil layers to external loads.

(3) The numerical calculation results verify that it is feasible to study the influence of root morphology on slope protection via the ABAQUS finite element software. The plant root morphology is greatly simplified in this paper, and the method used is a new attempt made in the aspect of quantitative slope protection effect of plant roots. Further research and discussion are needed so that this method can be applied in the ecological slope protection projects in the future.

Fund program: "Blue Project" for universities and colleges in Jiangsu; Jiangsu "Six Major Talent Highlands" Project; Natural Science Fund Program for universities and colleges in Jiangsu (18KJB220001); Science and Technology Project Plan of the Ministry of Housing and Urban-Rural Development (2016-K4-020);

About the author: JI Xiao-lei (1980-), male, associate professor, doctor, mainly occupied in environmental geotechnical and underground engineering researches. Email: jixlsuny@126.com

\section{References:}

1. Yanyan, Q. , Holden, N., Qi, F. , \& Meng, Z. . (2017). Influence of slope aspect on plant community composition and its implications for restoration of a chinese mountain range. Polish Journal of Environmental Studies, 26(1), 375-383.

2. Feng, T. , Wei, W. , Chen, L. , Jesús Rodrigo Comino, Die, C. , \& Feng, X. , et al. (2018). Assessment of the impact of different vegetation patterns on soil erosion processes on semiarid loess slopes. Earth Surface Processes \& Landforms, 43.

3. Shang, Y. J., Yue, Z. Q. , Yang, Z. F., Wang, Y. C. , \& Liu, D. A. . (2003). Addressing severe slope failure hazards along sichuan-tibet highway in southwestern china. Episodes, 26(2), 94-104.

4. Cao Z H, Zhao Q H, Zuo X Y, et al. Optimizing vegetation pattern for the riparian buffer zone along the lower Yellow River based on slope hydrological connectivity[J]. Ying yong sheng tai xue bao $=$ The journal of applied ecology / Zhongguo sheng tai xue xue hui, Zhongguo ke xue yuan Shenyang ying yong sheng tai yan jiu suo zhu ban, 2018, 29(3):739-747.

5. Wu, W. J. , Zha, T. G. , \& Zhang, Z. Q. . (2017). Effects of revegetation approach and terrain on plant species diversity as a result of converting croplands to forests in the loess region of western shanxi province, china. chinese journal of applied ecology, 28(4), 1121

6. Bischetti G B, Chiaradia E A, Simonato T, et al. Root strength and root area ratio of forest species in Lombardy (Northern Italy)[J]. Plant and Soil, 2005, 278(1/2): 11-22.

7. Gray D H. Biotechnical and soil bioengineering slope stabilization: a practical guide for erosion control[M]. Chichester: John Wiley and Sons, 1996 64-70.

8. CHEN $\mathrm{X}$ W, WONG $\mathrm{T} F, \mathrm{Ng} \mathrm{W} \mathrm{W}$, et al. Feasibility of biochar application on a landfill final cover - a review on balancing ecology and shallow slope stability[J]. Environmental Science and Pollution Research, 2016, 23(8):7111-7125.

9. JI X L, YANG P. A study on slope protection effect using the root system of bermuda grass based on fractal dimension[J]. Journal of Forestry Engineering, 2016,1(4):129-133.

10. Sen, P. , Kumar, D. , \& Ranjan, V. . (2017). Dump slope stabilisation through revegetation in iron ore mines in bonai iron ore range: a review. international journal of mining \& mineral engineering, 8(4), 334.

11. AKhil Garg,Ankit Garg,K.Tai. Estimation of factor of safety of rooted slope using an evolutionary approach $[\mathrm{J}]$.Ecological Engineering,2014(64):314-324.

12. Guangqian Du,Shijie Wang,Jichao Chu. Mechanism of Action Slope Vegetation[J].Advance Journal of Food Science andTechnology,2016(12):805-809.

13. Wang Gangyue,Li Jiong,Ye Feifan. Fuzzy Comprehensive Assessment Stability of Vegetated Slope with 3D Geomat Protection Using Cloud Model[J].The Open Civil Engeering Journal.2006(11):70-81.

14. J. R. Greenwood, J. E. Norris and J. Wint, Assessing the contribution of vegetation to slope stability[C], Geotechnical Engineering, 2004.

15. Dring. Fransesco, Ferraiolo. Application of inert materials in bioengineering[C]. Proceedings of the First Asia Pacific Conference on Ground and Water Bioengineering Erosion Control and Slope Stabilization, 1999.

16. Jianye, M. A., Zhanbin, L. I. , Bo, M. A. , He, W., Letao, Z. , \& Chaodong, L. I. . (2017). Soil water 
characteristics under different vegetation recovery modes in hilly and gully region of the loess plateau:a case study of the qiaozigou watershed. science of soil and water conservation.

17. Kim, J. H. , Fourcaud, T., Jourdan, C. , Maeght, J. L. , \& Stokes, A. . (2017). Vegetation as a driver of temporal variations in slope stability: the impact of hydrological processes. geophysical research letters, 44(10).

18. $\mathrm{Wu}$ J, Guo Y. An integrated method for quantifying root architecture of field-grown maize[J]. Annals of Botany, 2014(114): 841-851. 